\title{
a intertextualidade como elemento persuasivo em propagandas
}

\author{
${ }^{1}$ João Victor P.R., ${ }^{2}$ Daiane B.S.
}

1 universidade federal de minas gerais

2 universidade federal de minas gerais

• e-mail de contato principal: joaovcpr@ufmg.br

\section{resumo}

este trabalho analisa como a publicidade vale-se da intertextualidade como estratégia persuasiva, visto que a propaganda tem o propósito de influenciar opiniões ou de obter adesão para uma ideia (Lara \& Souza, 2007). Adotaremos a definição de dialogismo de Bakhtin (1997) e de intertextualidade em Maingueneau (2006). Foram selecionadas propagandas das seguintes empresas: SBT, Record, Netflix, Skol, McDonald's e Burger King, agrupadas em dois conjuntos. $\mathrm{Na}$ análise, foram explorados a disposição de informações; o eixo temático; o texto verbal; a composição gráfica; e o diálogo estabelecido entre os textos. Como resultados, foi percebido uma semelhança da disposição dos elementos imagéticos e dos enunciados entre as propagandas analisadas. A partir da divisão proposta em conjuntos, notou-se que as propagandas estabelecem ora uma relação clara e explícita, ora implícita. Portanto, a intertextualidade faz parte da estrutura textual do gênero e ela também age discursivamente a favor das propagandas.

palavras-chave: intertextualidade, propaganda, estratégia persuasiva.

\section{como citar este artigo}

Rocha, J.V.P., \& Soares, D.B. (2021). A intertextualidade como elemento persuasivo em propagandas. Revista Interdisciplinar em Estudos de Linguagem, 3(1), 12-22, doi https://doi.org/10.29327/224874.3.1-1 


\section{introdução}

Em consonância com Bakhtin (1997), a cada contexto de uso da língua surgem novos enunciados. A partir dessas interações sociais derivam-se os gêneros do discurso. Esses, por sua vez, devido a sua origem, são marcados sócio-historicamente. Isto é, refletem outros discursos que circulam entre os seus enunciadores. Esse entrelace de enunciados presentes na linguagem dos diversos discursos denota a característica dialógica da linguagem como expôs Bakhtin (1997). De acordo com Fiorin (2006), "O dialogismo são as relações de sentido que se estabelecem entre os dois enunciados" ( $p$. 164). É nesse diálogo entre os discursos que encontra-se a intertextualidade.

Desse modo, este estudo pretende investigar a presença, o uso e a interferência de mecanismos linguísticos e imagéticos indicadores intertextualidade na construção do caráter persuasivo das publicidades. Para tanto, foi feita a análise das publicidades uma feita pela emissora Record, outra pela empresa Netflix e a última pela emissora SBT - retiradas da versão online da revista Meio e Mensagem e da rede social Twitter. Também examinamos os anúncios publicitários da Burger King, McDonald's e Skol, veiculados na rede social Twitter, essas seguem em anexo.

As bases teóricas estão calcadas na explicação sobre o discurso publicitário de Ganzella (2015) e os conceitos bakhtinianos como o dialogismo, os gêneros do discurso, intertextualidade (Bakhtin, 1990; 1997), termos também discutidos, posteriormente, em Fiorin (2006). Ainda sobre a intertextualidade, mas agora tangendo discurso publicitário, ancoramos-nos em Knoll \& Pires (2010). Ademais, a análise de Aumont (2009) sobre os elementos constitutivos da imagem também foi um dos referenciais para este artigo.

Neste trabalho, considera-se fundamental o estudo o caráter dialógico da linguagem evidenciado pelo aspecto intertextual que o discurso publicitário apresenta, uma vez que é possível que muitas publicidades valeram-se e valem-se desse componente, a intertextualidade, para cumprir com o objetivo comunicativo do gênero publicitário (Knoll \& Pires, 2010). Em virtude da aproximação que a intertextualidade proporciona, tivemos como expectativa que as peças publicitárias usam a intertextualidade a fim de convencer seu público-alvo, tornando-o consumidor.

\section{pressupostos teóricos}

\section{gênero publicitário: seu discurso}

\section{e o texto argumentativo}

De acordo com Bakhtin (1997), todos os domínios da vida humana estão, de alguma maneira, ligados a língua. Por isso, essa se realizará de acordo com as especificidades do contexto no qual estão inseridos seus enunciadores. À vista disso, "cada esfera de utilização da língua elabora seus tipos relativamente estáveis de enunciados, sendo isso que denominamos gêneros do discurso" (Bakhtin, 1997, p. 290). Respaldados por essa conceitualização, consideraremos os anúncios publicitários como um gênero do discurso, enunciado de maneira escrita, e, além disso, multimodal, dada a sua composição verbal e imagética. Conforme com Sacchet \& Gomes (2006) citados em Knoll \& Pires (2010, p. 214), "os textos verbais e visuais têm na publicidade uma relação de complementaridade em que ambos os códigos operam na persuasão".

Segundo Marcuschi (2002), não é possível definir os gênero mediante certas propriedades que the devam ser necessárias e suficientes. Sendo assim, consideramos a finalidade da publicidade como o definidor desse gênero, pois "uma publicidade pode ter o formato de um poema ou de uma lista de produtos em oferta; o que conta é que divulgue os produtos e estimule a compra por parte dos clientes ou usuários daquele produto" (Marcuschi, 2002, p. 34)

Costa Lara \& Souza (2007) conceituam o anúncio como um gênero discursivo que tem como objetivo deflagrar uma determinada ideia, com fins de fomentar a adesão do leitor à mensagem. Assim, o gênero anúncio publicitário está diretamente vinculado à persuasão. Nesse tipo de texto, instigar a opinião do leitor potencializa a aceitação e a adesão do conteúdo disseminado. O objetivo disso é fazer com que o consumidor aceite a ideia divulgada pelo anúncio e, após isso, venha a adquirir um produto ou serviço. De acordo com Pitol (2017), "[a] sociedade de consumo vislumbra, na atividade publicitária, essencialidade ante a fundamentalidade", 
assim esse gênero torna-se crucial. Visto que é por meio dos textos publicitários que os possíveis consumidores em potencial se angariam, ou seja, persuadi-los a comprarem o produto anunciado e, além disso, seguirem a ideia/conceito que o anúncio também visa propagar.

Convém adentrar às definições e diferenciações entre publicidade e propaganda com o objetivo de esclarecer o porquê optou-se por utilizar do termo anúncio publicitário. Por vezes, essas palavras são dispostas como sinônimas, entretanto, a origem etimológica dos vocábulos é capaz de salientar as dissimilitudes presentes em seus significados.

Segundo Campos (2012), "o vocábulo 'propaganda' deriva de 'propagare', que significa tornar público, e nasceu no século XVI com a difusão da fé cristã." (p. 27). Portanto, "propaganda" seria o termo mais antigo. Já "publicidade" está associada às bases do capitalismo moderno. Sendo assim, "a propaganda serviria, então, para divulgar o produto, diferente de publicidade, que teria como meta a venda do produto. De acordo com estudos já realizados, publicidade seria ferramenta de mercado e propaganda seria disseminadora de ideias." (Campos, 2012, p. 27). Ainda segundo a autora, hodiernamente, há também divergência de traduções entre as áreas que usam esse o discurso publicitário que explicaria a confusão entre os usos dos vocábulos.

Quanto a estrutura da publicidade, convencimento é uma palavra comumente relacionada a esse gênero, devido à sua função de persuadir o interlocutor acerca de um produto, uma marca ou, até mesmo, uma ideia. Sendo um veículo de comunicação de massa, a publicidade fica responsável por deixar uma ideia, produto ou marca popularizados (Ganzella, 2016). Além disso, propaganda se constitui principalmente da divulgação de uma mensagem, tendo o propósito de influenciar opiniões ou de obter adesão para uma ideia (Lara \& Souza, 2007).

Contudo, o mero convencimento não é suficiente na venda de um produto ou serviço, afinal, nenhuma marca visa apenas persuadir seu consumidor de que seu produto é o melhor do mercado. Ela almeja que este consumidor passe a comprar o seu produto. "Assim, poderíamos afirmar que o objetivo final de uma publicidade é, de fato, provocar uma ação no consumidor." (Ganzella, 2015, p. 6).

O discurso publicitário possui alto caráter argumentativo, por isso a atividade perlocutória também é presente nos textos publicitários (Ganzella, 2015). Para que todas essas características sejam alcançadas, a publicidade se vale de elementos verbais e imagéticos.

A publicidade é um gênero semiótico
desenvolvido na sociedade de consumo, de
caráter argumentativo e finalidade
perlocutiva, utilizada por produtores de
bens para os dar a conhecer a indivíduos
(geralmente através dos meios de
comunicação social), persuadi-los e
influenciá-los com o fim de que estes os
adquiram [...] A publicidade não é uma
linguagem: é um gênero semiótico que
utiliza qualquer linguagem e que, com
frequência espantosa, faz uso da
combinação de vários procedimentos
comunicativos. (Ordóñez, 2002, p. 262,
citado em Ganzella, 2015, p. 7)

Por sua natureza persuasiva, a argumentação possui um papel essencial dentro do discurso publicitário, pois é por meio de argumentos lógicos que se consegue mudar a opinião de um leitor a fim de fazê-lo consumir um produto ou experimentar um serviço, ou seja, é necessário abrir um diálogo com o consumidor para que ele se convença do anunciado.

\section{dialogismo e intertextualidade}

Dialogismo, segundo Bakhtin (1997), em Estética da Criação Verbal, constitui-se como primeira condição de existência de qualquer discurso. Posto isso, ainda segundo o autor, não há discurso que já não seja existente e estes são ainda por outros discursos habitados. Assim, de acordo com Bakhtin (1997), o dialogismo é percebido como o eco de um discurso dentro de outros discursos, as vozes dos sujeitos, produtores do discurso, que continua a reverberar.

A orientação dialógica do discurso, é então que fundamenta a base dos fenômenos como a interdiscursividade e a intertextualidade. Sendo essa, por sua vez, um conjunto de relações explícitas ou implícitas que um texto mantém com outros textos, ou seja, uma propriedade constitutiva de todo texto (Maingueneau, 2006). Quanto 
aos conjuntos de relações, segundo Koch, Bentes \& Cavalcante (2012), citado em Abreu \& Santos (2019), eles ocorrem a partir das categorias: referência, citação e alusão. Sendo as primeiras pertencentes à intertextualidade explícita e, já a alusão, pertence à intertextualidade implícita.

Sendo assim, dialogismo e a intertextualidade apesar de distintos, ainda estão altamente correlacionados. E, como parte constitutiva da linguagem, o dialogismo possibilita o surgimento da intertextualidade.

Há claramente uma distinção entre as relações dialógicas e aquelas que se dão entre textos. Por isso, chamaremos qualquer relação dialógica, na medida em que é uma relação de sentido, interdiscursiva. O termo intertextualidade fica reservado apenas para os casos em que a relação discursiva é materializada em textos. Isso significa que a intertextualidade pressupõe sempre uma interdiscursividade, mas que o contrário não é verdadeiro. Por exemplo, quando a relação dialógica não se manifesta no texto, temos interdiscursividade, mas não intertextualidade. (Fiorin, 2006, p. 181)

É possível caracterizar a perspectiva de Bakhtin como pertencente à vertente da linguística chamada funcionalismo, visto que entende a língua como um organismo vivo, um fenômeno social, com função comunicativa e ideológica e sóciohistoricamente marcada (Campos, 2012). O ser e a linguagem se constituem quando vão ao encontro do outro e se inscrevem mutuamente. Com isso, revela-se o dialogismo como parte constituinte não só na linguagem, mas de todas as relações humanas em si. Segundo Bakhtin

A orientação dialógica é naturalmente um fenômeno próprio a todo o discurso. Tratase da orientação natural de qualquer discurso vivo. Em todos os seus caminhos até o objeto, em todas as direções, o discurso se encontra com o discurso de outrem e não pode deixar de participar, com ele, de uma interação viva e tensa. Apenas o Adão mítico que chegou com a primeira palavra num mundo virgem, ainda não desacreditado, somente este Adão podia realmente evitar por completo esta mútua orientação dialógica do discurso alheio para o objeto. Para o discurso humano, concreto e histórico, isso não é possível: só em certa medida e convencionalmente é que pode dela se afastar. (1990, p. 88)
Noções como polifonia, dialogismo e intertextualidade são cunhadas como bakhtinianas, sendo a última um conceito importante para os estudos linguísticos e literários. A ideia de intertextualidade é baseada na interseção, ou seja, um texto é um mosaico de outros textos. Esses partem do processo de absorção e de transformação de outro texto. Portanto, quando voltamos ao dialogismo, assumimos que não é o texto que dá vida à intertextualidade, mas sim, a intertextualidade é quem permite a existência do texto, pois somente o discurso do Adão mítico não seria inscrito por outro, isto é, seus enunciados seriam proferidos única e exclusivamente por ele.

O discurso é uma abstração, uma posição social marcada para além das relações dialógicas e pode ser vista como uma identidade (Brait, 2005). Dito isso, juntamente com a noção de polifonia e dialogismo, o interdiscurso é inerente ao intradiscurso, é uma parte constitutiva dele. Portanto, a relação interdiscursiva se dá por uma relação de sentido e entre enunciados. Logo, ao passo que a intertextualidade é a relação discursiva materializada em textos, a interdiscursividade é uma relação dialógica abstrata.

Considerando esse diálogo o constituinte da esfera mais importante da linguagem, ele dá suporte à teoria da intertextualidade, uma vez que ela é um procedimento de composição textual. Desse modo, todo texto tem em sua composição outros textos, os quais ficam presentes, em níveis diferentes, sob formas mais ou menos reconhecíveis (Fiorin, 2006).

\section{a imagem: dispositivo,}

\section{perspectiva e discurso}

A imagem é, antes de tudo, um objeto do mundo com características que a tornam perceptível. Em uma imagem, há vários elementos para observação e análise, porém este trabalho vai se ater aos elementos que colaboraram para a análise da persuasão nas propagandas.

Entre as características de uma imagem, o tamanho dela é fundamental para a análise desse dispositivo. Toda imagem é produzida para fazer parte de um ambiente, que the determina a visão (Aumont, 2009). As dimensões da imagem podem criar uma 
relação, por exemplo, de intimidade ou de identificação.

De acordo com Aumont (2009), o tamanho da imagem está entre os elementos essenciais na relação entre o espectador, o espaço físico e o espaço plástico da imagem. Por exemplo, obras de artes de grandes proporções tendem a deixar o espectador submetido a elas, enquanto outras obras de tamanho menor permitem que o espectador tenha, com a imagem um contato mais intimista (Aumont, 2009)

Se a imagem é um dispositivo que tem tamanho, tem dimensões, ela não é ilimitada. As imagens são, majoritariamente, objetos isolados perceptivelmente. Sendo assim, a noção de moldura encarnou essas características e, portanto, faz-se necessária na análise de imagens. Esse componente gráfico é o que dá formato à imagem. As diferentes formas de molduras existem para satisfazer uma série de funções. Uma dessas funções é a visual: a moldura é a primeira instância entre $\mathrm{o}$ mundo real e o mundo gráfico. Além disso, ela serve como transição entre o exterior e o interior da imagem. A moldura também contribui para lhe conferir a sua dupla realidade: dentro-fora e fora-dentro. A finalidade simbólica diz respeito à borda da imagem serve como um indicador para o espectador que diz como este deve olhar para a imagem, seguindo certas convenções. Por outro lado, a função retórica: em alguns contextos, a moldura pode ser compreendida como "comunicar um discurso" quase independente.

Vinda de uma dimensão cumulativa, a definição de Aumont (2009) sobre imagem autônoma e imagem em sequência provém da relação semântica entre dispositivos. A sequência é um conjunto de imagens que possuem coerência entre si mesmas e que mostram efeitos temporais comparáveis. (Aumont, 2009). Sendo assim, um anúncio publicitário em intertextualidade está ligado a outros anúncios também pelo componente imagético.

A imagem é uma representação, a qual é relacionada pelo seu espectador, com enunciados de naturezas ideológicas, culturais, sociais e em todo caso simbólicos, sem eles não faz sentido. Tais enunciados podem ser explícitos ou implícitos, por isso, é realizada a relação entre imagem e palavra. Pois, não há imagem puramente icônica, sempre haverá a intervenção da linguagem.

A imagem põe em jogo um sentido, este deve ser "decodificado" pelo destinatário. A semiologia afirma que há níveis de codificação da imagem: universais (percepção); naturais, porém socialmente formados (analogia) e sociais (contexto) (Aumont, 2009) O domínio desses diferentes níveis será variável de sujeito para sujeito e suas situações históricas, o que implicará em interpretações diferentes. Tendo isso em consideração, uma propaganda, a qual é um gênero que envolve tantos elementos gráficos e verbais, pode causar uma diversificação de sentidos em cada consumidor em potencial.

\section{análise}

As peças publicitárias, cujo estudo nos ateremos nesta seção, são compostas de elementos verbais e não-verbais. A investigação foi dividida em dois momentos: (i) análise das propagandas envolvendo o apresentador de TV Silvio Santos e a série televisiva Breaking Bad (doravante conjunto P1) ${ }^{1}$, e (ii) análise das publicidades envolvendo as empresas de fast food Burger King e McDonalds e a empresa de bebida Skol (doravante conjunto P2).

No caso do conjunto P1, examinamos apenas as peças publicitárias. Enquanto no conjunto P2, além dos anúncios, investigamos também os tweets que acompanham as peças postados pelas empresas envolvidas. A Tabela 1 mostra a divisão de cada conjunto de propagandas. 
Tabela 1

Divisão de conjuntos de propagandas

\begin{tabular}{ccc} 
& $\begin{array}{c}\text { Marcas } \\
\text { envolvidas }\end{array}$ & $\begin{array}{c}\text { Elementos } \\
\text { analisados }\end{array}$ \\
\hline Conjunto P1 & $\begin{array}{c}\text { Rede } \\
\text { Record } \\
\text { Netflix } \\
\text { SBT }\end{array}$ & $\begin{array}{c}\text { Verbais e não } \\
\text { verbais apenas nas } \\
\text { peças publicitárias }\end{array}$ \\
\hline $\begin{array}{ccc}\text { Conjunto P2 } \\
\text { (em anexo) }\end{array}$ & $\begin{array}{c}\text { Burger King } \\
\text { McDonald's } \\
\text { Skol }\end{array}$ & $\begin{array}{c}\text { Verbais e não } \\
\text { verbais nas peças } \\
\text { publicitárias e nos } \\
\text { tweets }\end{array}$
\end{tabular}

Fonte: elaboração dos autores

Nas próximas subseções iremos discutir os elementos de intertextualidade que contribuem para a persuasão das peças aqui analisadas.

\section{análise do conjunto $P 1$}

O contato do apresentador Silvio Santos com a série de TV Breaking Bad é o tema da peça publicitária da Record. Essa relação é usada para promover o próprio canal televisivo, pois na televisão aberta a série se passava no canal em questão.

Como primeiro componente de divulgação da Record, destaca-se a frase principal "O programa do Silvio Santos é assistir ao Breaking Bad.". Esse slogan se diferencia do resto do texto da publicidade para que chame atenção do leitor. Bem como o tamanho da frase principal, o texto secundário, logo abaixo do texto em fonte maior, de certa maneira, confirma o que é dito no slogan. A frase "Está comprovado: quem gosta de televisão, não perde um episódio de Breaking Bad" serve como uma promoção da Record, porque, para assistir à série na televisão aberta, é necessário assistir por meio do canal Record. Já "Faça como o Silvio Santos" serve para que o consumidor em potencial não tenha dúvidas sobre a proposição de que Silvio Santos acompanha o seriado Podemos dizer que esses mecanismos dão credibilidade ao slogan da propaganda da Record.

No tocante à peça publicitária da Netflix, ao comparar com a publicidade da Record, pode-se perceber claramente uma relação intertextual de referência, visto que elas têm elementos em comum. Em primeiro lugar, o slogan "O programa do Silvio Santos é assistir ao Breaking Bad" é um elemento constitutivo em comum nas duas peças. Adicionado a isso, o aspecto visual da frase permanece o mesmo nas duas propagandas, isto é, ambas têm as mesmas fontes, dimensões e diagramação. Se pensarmos na intertextualidade como retomada de elementos de outros textos (Maingueneau, 2006), a imitação também entra nessa definição, pois se trata de uma recuperação de elementos por meio da réplica.

Tanto na publicidade da Record quanto na peça da Netflix, existe outro elemento de menção ao Silvio Santos assistindo a Breaking Bad: o sintagma "o programa do Silvio Santos". Tal expressão pode ser associada a duas possibilidades de sentido: (i) como entretenimento, o apresentador de TV assiste ao seriado e (ii) o programa de auditório que Silvio Santos apresenta trata-se de ver episódios de séries não pertencentes ao SBT. Considerando a segunda hipótese, seria pretendido um efeito de humor, pois é, no mínimo, contraditório um canal de TV passar programação de uma concorrente.

Além disso, as propagandas da Record e da Netflix possuem o fundo fosco, diferenciando apenas nas cores, para simular a distribuição de cores em uma tabela periódica bem como dar destaque à marca, visto que a cor do fundo corresponde à cor principal da empresa. De forma similar, as fontes de texto são semelhantes, o que ajuda - leitor a relacioná-las mais facilmente. Outro fator importante é a disposição das logomarcas, a qual também é correlata: o símbolo do seriado fica à esquerda e o símbolo da emissora fica à direita. Esses elementos visuais corroboram a ideia de que o anúncio da Netflix é muito semelhante ao texto da Record. Portanto, isso demonstra que os elementos visuais também são elementos que trazem outras vozes de discurso, produzindo uma rede de intertextos.

Um elemento intertextual na propaganda da Netflix é o texto secundário (abaixo da frase maior). A maioria das sentenças dessa parte do texto são cópias exatas da propaganda da Record, diferenciando apenas a última, "Faça como o Silvio Santos, assine a Netflix". Nesse caso, a empresa de streaming muda a última frase 
para que consiga estabelecer a relação da série com o apresentador, assim como foi feito na propaganda da Record, além de poder promover a empresa e de desvincular Breaking Bad ao canal Record.

Tendo em vista a linearidade temporal da publicação, consideramos a propaganda da Record como o texto disparador. Determinamos o termo "texto disparador", visto que, apesar de que a intertextualidade está presente nas variadas materialidades linguísticas, um texto possui certos graus de autonomia e de unicidade, portanto nem todos elementos do texto são "gatilhos" para outros. Desse modo, devido à dimensão temporal e aos elementos constitutivos mencionados, podemos considerar a propaganda da Netflix como um intertexto em relação à propaganda da Record. No Diagrama 1 abaixo, essa direcionalidade da intertextualidade é demonstrada pela seta pontilhada, sendo que o texto disparador é a fonte da seta. Enquanto o círculo, denominado domínio, são os outros textos e gêneros que as propagandas resgatam e que não serão abordados neste trabalho e o quadro cinza é a materialidade verbal e nãoverbal das propagandas. A seta na parte inferior mostra a linha do tempo.

\section{Diagrama 1}

Direcionalidade da intertextualidade no conjunto P1 (parcial)

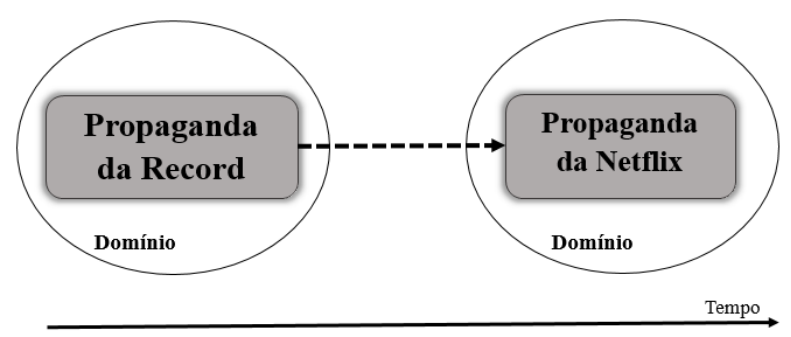

Fonte: elaboração dos autores

Como estratégia de retomada das duas publicidades anteriores, a campanha do SBT coloca uma manchete sobre a disputa da imitação entre Record e Netflix ${ }^{1}$. Essa recuperação textual se dá por meio da menção explícita das outras empresas e faz com que o leitor associe o anúncio do SBT a essas publicidades anteriores. Desta maneira, esse procedimento intertextual auxilia na compreensão, visto que há uma coerência interna entre as peças publicitárias.

Contrastando a propaganda do SBT com as outras duas, percebe-se que alguns elementos não foram mantidos, como feito pelo Netflix. A disposição do logotipo da empresa se encontra no canto direito da imagem. Além disso, todo o texto está escrito na fonte do texto destaque das outras propagandas, o que realça a mensagem transmitida. Como elemento relacional mais forte, podemos mencionar a manchete no topo da propaganda do SBT que indica a disputa entre as outras duas empresas, remetendo às duas propagandas anteriores.

Embora haja também certa semelhança entre as propagandas com o fundo fosco e a fonte do texto, uma consideração curiosa é que a propaganda do SBT se estabelece como um intertexto no tocante à relação das duas outras propagandas. A peça publicitária do SBT não é uma cópia quase literal como a da Netflix. De fato, considerando a disputa judicial causada pela cópia da Netflix, a propaganda do SBT usa a intertextualidade das demais peças publicitárias como tema e não como um componente textual. $\mathrm{O}$ anúncio do SBT se configura, portanto, como uma alusão em relação aos outros anúncios. O diagrama 2 mostra como a direcionalidade da intertextualidade muda quando consideramos esse encadeamento. O retângulo pontilhado ilustra a relação interna instituída entre as propagandas da Record e da Netflix.

Diagrama 2

Direcionalidade da intertextualidade no conjunto P1 completa

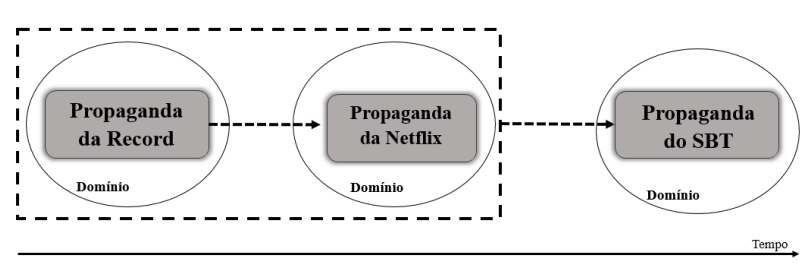

Fonte: elaboração dos autores

Isso que dizer quer que o SBT utilizou da conexão polêmica entre as duas outras propagandas e usou ao seu favor, principalmente resgatando um dos elementos principais, o apresentador Silvio Santos. O texto da propaganda ainda evidencia como o 
SBT está usando a disputa como fomento ao próprio canal com a frase "Ele [Silvio Santos] faz o que mais gosta: aumenta a audiência do SBT".

\section{análise do conjunto P2}

De forma geral, o tema em comum dos três anúncios publicitários do conjunto P2 é a promoção de certo produto. Skol, McDonald's (MD) e Burger King (BK) divulgam a oferta de desconto de seus produtos. Como se dá essa exposição do desconto é o nosso objeto de análise nesta seção.

A propaganda da Burger King possui uma estrutura relativamente simples. Primeiramente, a publicidade da empresa expõe a promoção de um combo por $R \$ 19,90$. Utilizando suas cores principais, essa marca usa um fundo de uma parede sem foco com a logomarca no canto superior esquerdo. Nesta propaganda, é exposto também uma imagem ilustrativa dos elementos pertencentes ao combo em desconto.

Enquanto isso, o anúncio da empresa fast food McDonald's explicitamente copia a publicidade da Burger King. No que diz respeito ao texto, a MD fez o mesmo tipo de promoção que a BK fez bem como a disposição gráfica também é semelhante. Além disso, a região em que a foto do produto e a logomarca estão na propaganda da MD é equivalente à região desses elementos na propaganda da BK. Um fator quase idêntico entre os anúncios da BK e da MD são os produtos do combo em promoção. Ambas promoções envolvem: aperitivo, sanduíche, bebida, sorvete e batata frita, revelando novamente a associação entre elas.

Por uma questão temporal, e explicitado por algumas notícias, a peça publicitária da BK é o texto disparador do conjunto P2. O Diagrama 3 ilustra a intertextualidade das duas propagandas.

\section{Diagrama 3}

Direcionalidade da intertextualidade no conjunto P2 (parcial)

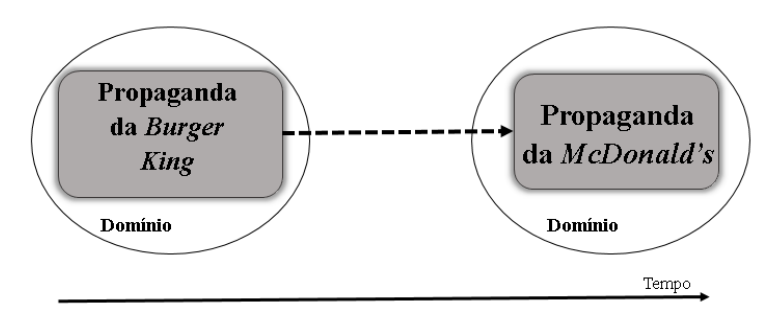

Fonte: elaboração dos autores

No entanto, os componentes que denunciam a cópia mais latentemente estão fora do texto (verbal e não-verbal) das peças publicitárias. O primeiro deles é onde a foto foi tirada, porque as duas propagandas (BK e MD) estão uma ao lado da outra, evidenciando a quem as vê os aspectos que são em comum e, assim, destacando a relação de quase reprodução que há entre elas. Seguindo a direção de leitura (da esquerda para a direita), ao chegar na propaganda da MD, o consumidor-leitor pode estranhar a semelhança e considerar o anúncio da BK como a "original". Outro componente que salienta essa afinidade é o tweet publicado na conta da empresa BK, "Posso copiar? Claro. Só não faz igual.". Essa frase do tweet tem um efeito essencial na percepção da reprodução do anúncio, porque, desse modo, a BK explicita que está fazendo uma crítica à MD e, até certo grau, faz uma caricatura do texto. Em outras palavras, o tweet tem um impacto humorístico que ajuda o internauta a entender a relação entre as publicidades.

Querendo participar desse jogo, a empresa Skol responde ao tweet da BK com a mesma oferta de desconto que a $\mathrm{MD}$ e a BK fizeram (4 itens por $R \$ X X$ ). A organização gráfica é similar: logomarca no canto superior direito, valor dos itens em promoção no meio da parte superior e imagem dos produtos no meio.

Assim como na peça da MD, além de itens verbais e semióticos, o que desvela a relação de intertextualidade entre as publicidades é relacionado também à disposição da foto e ao tweet. Colocando as propagandas lado a lado, explicita-se como elas têm componentes parecidos. Da mesma forma, o tweet "É meme?" traz um teor satírico 
para a cópia das peças publicitárias, visto que "meme" é um texto por natureza humorístico. Além disso, com essa abordagem irônica do tweet, a Skol critica a ação da MD sobre copiar a publicidade da BK, e, já que o meme tem um teor de humor, ou seja, não é prototipicamente levado seriamente, a ação da MD é comparada a uma brincadeira. No entanto, a Skol usa isso a seu favor e também reproduz a estrutura do anúncio da MD e, por consequência, da BK. A publicidade da Skol se põe, portanto, como "a cópia da cópia". O Diagrama 4 demonstra a intertextualidade entre os textos do conjunto P2. A seta combinada (pontos e linhas) retrata a relação da peça da BK, como texto disparador primário, e o anúncio da Skol.

\section{Diagrama 4}

Direcionalidade da intertextualidade no conjunto P2 completa

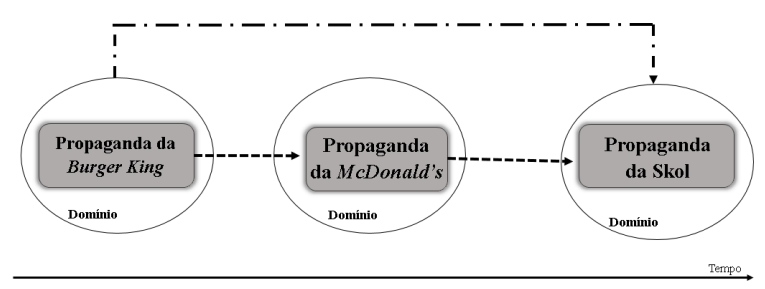

Fonte:elaboração dos autores

\section{considerações finais}

A intertextualidade é um elemento que realiza-se nos mais variados tipos de textos, isto é, não só os poemas, contos e romances, mas também em textos midiáticos. Por isso, este trabalho teve como objetivo investigar como o caráter persuasivo em propagandas pode ser construído por meio de elementos intertextuais. Os criadores dos anúncios refletem sobre como cada elemento do texto pode corroborar com a ideia de atrair consumidores em potencial. Os criadores podem, portanto, lançar mão da intertextualidade como recurso de persuasão.

Conforme Knoll \& Pires (2010), "[c]omo o texto é uma manifestação não só de ordem verbal, mas de outras naturezas semióticas, considera-se que a intertextualidade está presente também nas imagens."(p. 214). Esse escopo multimodal da intertextualidade é um elemento essencial para o entendimento das relações entre as propagandas analisadas, visto que não só elementos tipicamente verbais, mas também componentes imagéticos e espaciais agiram como operadores intertextuais.

Considerando a intertextualidade como uma recuperação de elementos de outros textos, formando então um mosaico e rede de textos, as propagandas analisadas usaram desse recurso para criar um contato mais próximo com o público alvo, que é possibilitado por meio da intertextualidade. Em virtude dessa aproximação, tivemos como expectativa que, a fim de convencer o público alvo, a publicidade o angaria como consumidor ao valer-se da aproximação e referenciação que a intertextualidade proporciona por meio do entrelaçamento dos discursos.

No caso das peças do conjunto $P 1$, não só elementos verbais, como o slogan, e nãoverbais, como a disposição de informações, mas também desencadeamentos textuais incorporam a intertextualidade entre as propagandas desse grupo, gerando, assim, uma rede de intertextos. Da mesma maneira, esses elementos, como operadores intertextuais, se mostram como componentes importantes para a argumentação na propaganda em busca de aderência por parte do consumidor em potencial.

Semelhantemente as publicidades do conjunto P2 formam uma rede de intertextos. Consideramos que, além dos aspectos verbais e imagéticos presentes nas peças, o grupo P2 usa de elementos fora da publicidade para marcar a relação entre elas, neste caso os tweets. Isso demonstra que a intertextualidade em propagandas é um elemento que pode ultrapassar dos limites da própria peça publicitária. Os elementos verbais, inclusive os tweets, e os aspectos imagéticos contribuíram para que a relação entre os textos do conjunto P2 fosse uma associação intertextual.

Em vista disso, propagandas e publicidades são gêneros textuais que são muito propensos em enriquecer o campo dos estudos das linguagens, tendo em vista suas características multimodais. Considerando principalmente o fenômeno intertextual, as propagandas podem formar explicitamente redes de textos que constroem certo grau de coerência entre si. Além disso, elas podem ter essa rede como componente constitutivo para causar uma ação nos consumidores em 
potencial, ou seja, persuadi-los a comprarem o produto anunciado ou seguirem a ideia apresentada.

\section{referências}

Abreu, M. T. T V.; Santos, C. N. (2019). As relações de intertextualidade conforme as funções discursivas anafóricas no gênero digital comentário no Facebook. Texto Livre: Linguagem e Tecnologia, 12(1),19-36

Aumont, J. (2009). A imagem. Lisboa: Editora Edições Texto e Grafia.

Bakhtin, M. (1990). Questões de literatura e estética: a teoria do romance. São Paulo: Hucitec.

Bakhtin, M. (1997). Estética da criação verbal. São Paulo: Martins Fontes.

Campos, R. C. S. (2012). Anunciou - vendeu? O anúncio publicitário na mídia impressa e os mecanismos de sua construção como gênero: uma análise funcional-discursiva. Tese (Doutorado). Universidade Federal de Minas Gerais, Belo Horizonte, Minas Gerais, Brasil.

Fiorin, J. L. (2006). Interdiscursividade e intertextualidade. In B. Brait (Org.). Bakhtin: outros conceitos chaves. São Paulo: Editora Contexto, 161-194.

Ganzella, L. M. (2015). Análise do discurso e a linguagem publicitária: um estudo de caso. Interletras, 4(22), 1-13.

Chabrol, C. (2008). Humor e mídia: definições, gêneros e cultura. In G. M. P. Lara, I.L. Machado \& W. Emediato (Orgs.). Análise do discurso hoje, v. 2. Rio de Janeiro: Editora Nova Fronteira, 221-234.

Knoll, G. F. \& Pires, V. L. (2010). Intertextualidade e propaganda: análise de processos intertextuais em anúncios impressos. Anais do Seminário Internacional de Texto, Enunciação e Discurso, Porto Alegre, 210-216.

Lara, A. G. C.; Souza, L. C. P. (2007). O gênero propaganda na escola: uma análise das aulas de leitura. Gatilho, 6(1), 1-11.

Maingueneau, D., Barbosa, M. V. \& Lima, M. E. A. T. (2006). Termos-chave da análise do discurso. Belo Horizonte: Editora UFMG.
Marcuschi, L. A. (2002) Gêneros textuais: definição e funcionalidade. In A. P. Dionísio, A. R. Machado \& M. A. Bezerra (Orgs.). Gêneros textuais e ensino. Rio de Janeiro: Lucerna.

Possenti, S. (2010). Humor, língua e discurso. (1a ed.), São Paulo: Editora Contexto.

Pitol, Y. U. (2017). A publicidade infantil na sociedade de consumo: uma análise empírica da publicidade e de sua (in)conformidade com o direito brasileiro. Dissertação (Mestrado). Universidade La Salle, Canoas, Rio Grande do Sul, Brasil.

Meio e Mensagem. (2014). Record planeja processar Netflix. Recuperado em 10 de novembro de 2017 de https:// www.meioemensagem.com.br/home/midia/ 2014/02/13/record-planeja-processarnetflix.html

Meio e Mensagem. (2014). SBT entra na polêmica de Record e Netflix. Recuperado em 10 de novembro de 2017 de https:// www.meioemensagem.com.br/home/midia/ 2014/02/17/sbt-entra-na-polemica-derecord-e-netflix.html

Vale, R. P. G. (2014). Argumentação na mídia, problematicidade e imitação nos gêneros transgressivos. Revista Eletrônica de Estudos Integrados em Discurso e Argumentação, 6(1), 138-152.

recebido em 14/08/2020 aceito em 09/10/2020 
anexos

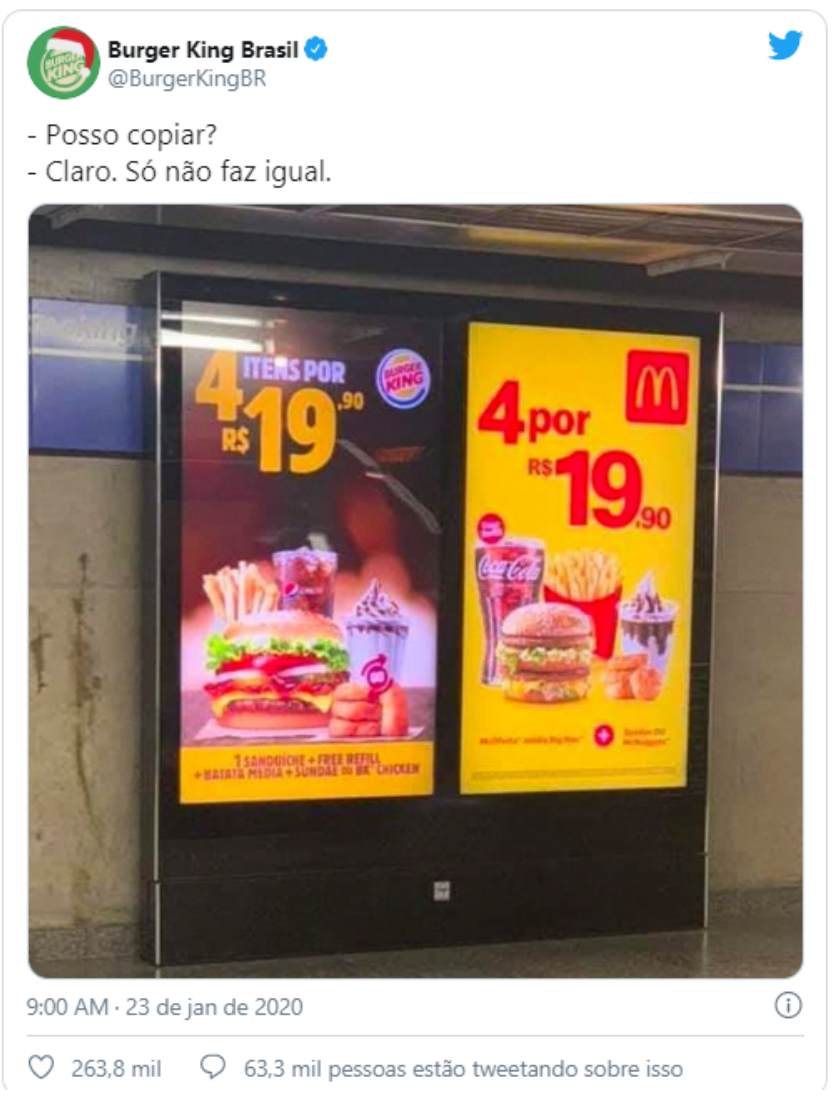

\section{2)}

É meme?

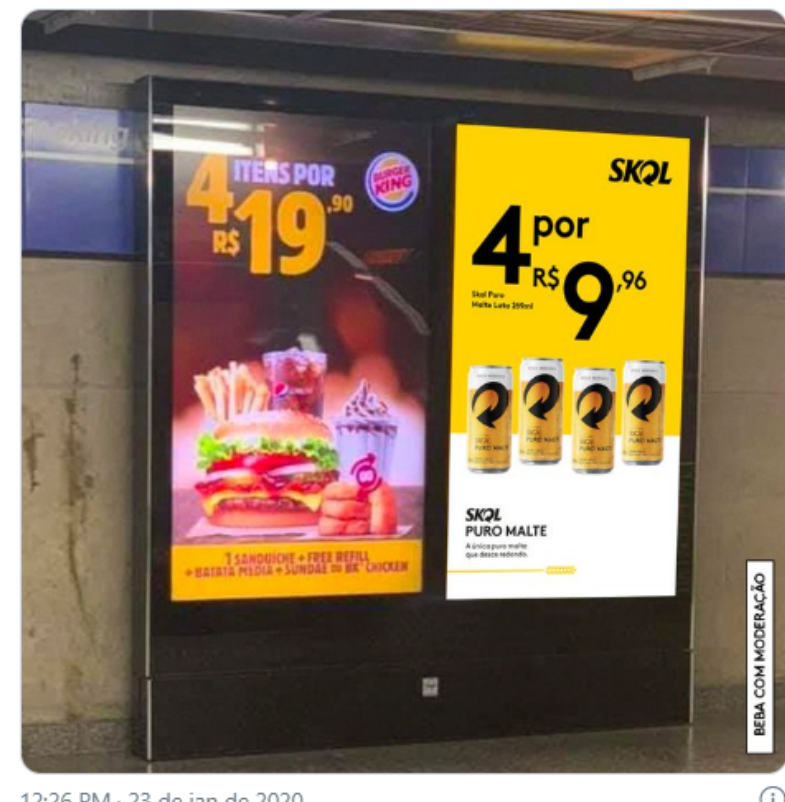

12:26 PM · 23 de jan de 2020

(i)

○ 11,4 mil $Q 1,2$ mil pessoas estão tweetando sobre isso 